\title{
Seroprevalence of Hepatitis C in Chronic Hemodialysis Patients in Marrakesh Region
}

\author{
Lamiae Arsalane ${ }^{1,}$ *, Abderrahman Boukhira ${ }^{2}$, Karima Azizan $^{1}$, Youssef Kamouni ${ }^{1}$, Said Zouhair ${ }^{1}$ \\ ${ }^{1}$ Bacteriology-Virology Department, Avicenna Military Hospital Marrakech, Faculty of Medicine, Cadi Ayyad University, Marrakech, \\ Morocco \\ ${ }^{2}$ Department of Biochemistry-Chemistry, Avicenna Military Hospital Marrakech, Faculty of Medicine, Cadi Ayyad University, Marrakech, \\ Morocco
}

Email address:

arsalanelamiae@yahoo.fr (L. Arsalane)

${ }^{*}$ Corresponding author

\section{To cite this article:}

Lamiae Arsalane, Abderrahman Boukhira, Karima Azizan, Youssef Kamouni, Said Zouhair. Seroprevalence of Hepatitis C in Chronic Hemodialysis Patients in Marrakesh Region. American Journal of Laboratory Medicine. Vol. 4, No. 2, 2019, pp. 31-34.

doi: 10.11648/j.ajlm.20190402.11

Received: October 9, 2018; Accepted: November 5, 2018; Published: April 29, 2019

\begin{abstract}
Infection with the hepatitis $\mathrm{C}$ virus $(\mathrm{HCV})$ is a major global public health problem. The objectives of this study are to evaluate the seroprevalence of hepatitis $\mathrm{C}$ in chronic hemodialysis patients, a category of patients at particular risk of hepatitis $\mathrm{C}$ virus transmission, and to identify the main risk factors for infection. This is a prospective study conducted from January 1st, 2015 to December 31st, 2017, including 600 chronic hemodialysis patients treated at 5 centers in the Marrakech region. Patients were tested for anti-HCV antibodies by chemiluminescent microparticulate immunoassay (CMIA). The confirmation is carried out by ELISA. The statistical analysis was performed using the SPSS statistics 17.0 software. The prevalence of anti-HCV antibodies is $15 \%$. There is no statistically significant difference between the groups of HCV-infected and non-HCV-infected patients in terms of age, sex, and number of RBCs transfused. In contrast, the median hemodialysis duration and the number of attended hemodialysis centers were significantly higher in the HCV + group $(p<0.001)$. The factor transfusion long incriminated, loses its importance. On the other hand, seniority in hemodialysis and the number of centers frequented seem to be contributing factors. Adherence to hygiene measures and the rigorous application of prevention recommendations against $\mathrm{HCV}$ transmission could further improve the prevalence of hepatitis $\mathrm{C}$ in dialysis units.
\end{abstract}

Keywords: Chronic Hemodialysis, Hepatitis C, Prevalence

\section{Introduction}

Hepatitis $\mathrm{C}$ virus (HCV) infection is a major public health problem on a global scale. In 2015, the World Health Organization (WHO) estimated that $3 \%$ of the general population was infected with this virus, and 130 to 170 million individuals were chronic carriers of hepatitis $\mathrm{C}$ [1]. The prevalence of $\mathrm{HCV}$ infection is higher in hemodialysis patients than in the general population and is associated in these patients with a higher mortality rate compared to uninfected dialysis patients [2]. In Morocco, the prevalence of $\mathrm{HCV}$ in dialysis varies widely between regions, ranging from $11 \%$ to more than $85 \%$ [3]. The objectives of this study are to determine the seroprevalence of viral hepatitis $\mathrm{C}$
(HCV) in chronic hemodialysis patients in Marrakesh region and the main risk factors associated.

\section{Method}

\subsection{Type, Location and Duration of the Study}

This is a descriptive analytical and prospective study carried out in Bacteriology-Virology Department at the Military Hospital Avicenna (HMA) of Marrakesh, from January 1, 2015 to December 31, 2017. During this period, 600 serological analyses were conducted for the investigation of the hepatitis $\mathrm{C}$ virus antibodies. 


\subsection{Patients}

The study involved 600 patients with chronic renal failure who were managed by periodic hemodialysis in five hemodialysis centers at the regional level of Marrakesh. In order to highlight the risk factors for contamination, demographic, clinical, biological and dialytic parameters were studied and compared in two groups of patients: Infected and non-infected patients.

The collection of data from each patient was done through the careful exploration of medical records, and the questioning at the beds of patients, to bring additional information. We have recorded the data respecting the anonymity of patients and centers, as well as the confidentiality of their information after agreement.

\subsection{Serological Tests}

During our study, a sterile dry-labeled blood sample (name, first name and serial number) was performed for each patient. Samples were sent to the HMA virology laboratory within one hour of sampling $\left(+4^{\circ} \mathrm{C}\right)$. The samples were centrifuged for $15 \mathrm{~min}$ at $4000 \mathrm{rpm}$, and the serum thus recovered, sterile aliquot in two samples, one for frozen relative backup at $\left(-20^{\circ} \mathrm{C}\right)$, and the second for frozen absolute backup at $\left(-80^{\circ} \mathrm{C}\right)$. Hepatitis $\mathrm{C}$ serology tests were performed on the ARCHITECT 11000 SR (Abbott Diagnostics). The research technique is based on chemiluminescent microparticle immunoassay (CMIA). The reagent samples for anti-HCV $\mathrm{Ab}$ in our series are reanalyzed by ELISA (Enzyme Linked Immuno Sorbent Assay) on Evolis automaton (Biorad).

\subsection{Statistical Analysis}

The statistical analysis was carried out using SPSS statistics 17.0; Quantitative variables were expressed as mean, standard deviation or median and percentiles, while qualitative variables were expressed as numbers and percentages. We subdivided our sample into two groups for the study of risk factors: "HCV +" group and "HCV -" group. For statistical analysis, we used Student's t-test and chi-2.A p $<0.05$ was considered significant.

\section{Result}

\subsection{General Characteristics of the Population Studied}

\subsubsection{Demographic Datas}

The study involved 600 patients treated with periodic hemodialysis at the 5 centers participating in the study. The average age of patients is 54,5 years old with extremes ranging from 16 to 92 years old. A slight male predominance (305 men or $51 \%$ ) is noted, the sex ratio is 1.04 .

\subsubsection{Clinical Symptomatology}

In our study, no patient presented clinical symptoms related to liver injury. In fact, the serology was carried out as part of the systematic review of serological surveillance.

\subsection{Patients with Hepatitis C}

In this study, the anti-HCV antibodies were detected in 510 patients. The overall seroprevalence of $\mathrm{HCV}$ was therefore $15 \%$. Two groups of hemodialysis patients were compared: those with $\mathrm{HCV}+$ serology (90 patients) and those with HCV - serology (510 patients).

\subsubsection{Demographic Datas}

The average age in the group of patients with HCV is 57 years old with extremes ranging from 30 to 87 years, and 53 years old with extremes ranging from 16 to 92 years in the group of HCV patients negative : the difference between the two groups is not significant $(\mathrm{p}=0.390)$. The most affected age group was between 46 and 55 years old.

Among the HCV-positive patients, there is a slight female predominance with 50 women or $55 \%$, against 40 men or $45 \%$, whereas in the HCV negative group, there is a slight male predominance with 312 men or $52 \%$ : the difference between the two groups is not significant $(p=0.261)$.

\subsubsection{Dialysis Data}

Comparison of dialysis data between $\mathrm{HCV}+$ and $\mathrm{HCV}$ patients - showed that only differences in the number of centers attended and seniority in hemodialysis were significant $(\mathrm{p}<0.001)$. In fact, all our $\mathrm{HCV}+$ patients had attended more than 2 hemodialysis centers, unlike HCV patients - $90 \%$ of whom had attended only one center. Similarly, the comparison between the prevalence of three groups: treatment less than 2 years; between 2 and 5 years and above 5 years revealed a significant difference $(\mathrm{p}=$ 0.001 ) and therefore the association between the seniority of hemodialysis treatment and the positivity of anti-HCV Ab is important."'Table 1"

Table 1. Seniority in hemodialysis and HCV contamination.

\begin{tabular}{llll}
\hline $\begin{array}{l}\text { Seniority in } \\
\text { hemodialysis (years) }\end{array}$ & $\begin{array}{l}\text { Patients HVC }- \\
(\mathbf{n} / \%)\end{array}$ & $\begin{array}{l}\text { Patients HVC }+ \\
(\mathbf{n} / \%)\end{array}$ & P* \\
\hline$<2$ & $92(18 \%)$ & $6(6.7 \%)$ & \\
$2-5$ & $227(44.5 \%)$ & $26(28.8 \%)$ & $<0.001$ \\
$>5$ & $191(37.5 \%)$ & $58(64,4 \%)$ & \\
\hline
\end{tabular}

*The threshold of significance was set at 0.05

A history of blood transfusion was noted in both the HVC + and HCV - groups, with a frequency of $68.3 \%$ in patients with viral hepatitis $\mathrm{C}$, and $59.3 \%$ in the uninfected group. In our study, no patient was transfused before 1994 (date of onset of anti-HCV Ab in blood donors in Morocco). The number of red blood cells transfused since the start of dialysis is $4.44 \pm 2.73$ pellets in the $\mathrm{HCV}+$ group, compared to $3.4 \pm 3.35$ in the HCV - group. The difference is not significant.

\section{Discussion}

$\mathrm{HCV}$ infection is a real public health problem in the world; in 2015 , WHO estimated that $3 \%$ of the general population was infected with this virus, and that 130 to 150 million 
people are chronic carriers of hepatitis C. It is also responsible for the death of around 500,000 people by liver diseases [1]. Hemodialysis is a population particularly exposed to this infection, because of the regular vascular access and the alteration of immune defenses induced by chronic renal failure. The seroprevalence of HCV infection in this population has been studied since the early 1990s, varies from one country to another and in the same country from one region to another, or even from one country to another one hemodialysis unit to another. [2]

The mean age of our HCV positive patients is 54,5 years. In the literature, the average age is between 43.5 years and 55.4 years [8]. The study of the seroprevalence of HCV by sex showed a slight predominance of women. These results are in agreement with those obtained by a study conducted at Ibn Rochd University Hospital in Casablanca in 2005, others reported a male predominance $[8,12,15]$.

In this study, the anti-HCV antibodies were detected in 510 patients. The overall seroprevalence of $\mathrm{HCV}$ was therefore $15 \%$. At the global level, a meta-analysis published in 2008 in the "American Journal of Nephrology" gathering all the studies carried out on the seroprevalence of HCV in HDC, since 1999, until 2007, showed that the highest seroprevalences $(>40 \%$ ) were observed in Brazil, Peru, Senegal, Syria, Tunisia, Pakistan, Saudi Arabia, and Iran [4]. Other more recent studies also report high values in Yemen (40.2\%) and Libya 31.1\% [5.6]. Nevertheless, the seroprevalence reported in this study remains higher than that reported in India in Lucknow (6.99\%) [7]. At the national level, several studies have been conducted to determine the seroprevalence of hepatitis $\mathrm{C}$ in HDC. They showed prevalences ranging from 18.4 to $76 \%$. Thus, the seroprevalence found in our study is lower than all those published so far on the seroprevalence of HCV in HDC in Morocco. 35.5\% in Fez in 2009, 33.4\% in the Rabat-salé region, Khmisset and Meknes in 2010, 24.7\% in Oujda in 2012 [8-10]. But these seroprevalence figures remain higher compared to the general population of Morocco, where the prevalence of $\mathrm{HCV}$ is estimated at $1.93 \%$, and the blood donor population where it is $1.08 \%[3,11]$.

In addition, several factors have been implicated in the prevalence of $\mathrm{HCV}$, but the most commonly cited are transfusion and duration of hemodialysis. Blood transfusion is among the most incriminated factors. This could be explained by the frequency of transfusions in the hemodialysis population, especially before the introduction of routine screening for this virus in labile blood products. In Morocco, detection of $\mathrm{HCV}$ in blood products was introduced in 1994. In the Bahadi study, patients transfused before 1994 were three times more likely to get hepatitis C than those transfused after that date [12]. In our study, no hemodialysis was transfused before 1994. Bahadi et al reported that the mean number of packed red blood cells in $\mathrm{HCV}+$ was $2.59 \pm 2.45$ vs. $1.6 \pm 1.9$ in the $\mathrm{HCV}+$ group, with a significant difference between the two groups. The risk of hepatitis $\mathrm{C}$ has increased threefold when this number exceeds three red blood cells. Similar results have been reported in several studies [12]. At the level of our study, the average number of packed cells is $4.44 \pm 2.74$ in $\mathrm{HCV}+$ against $3.4 \pm 3.35$ for HCV-but without significant difference. This could be explained by the regression to the use of transfusion as a treatment for anemia, since erythropoietin was used in Morocco in the early 2000s.

Numerous studies have demonstrated a positive relationship between $\mathrm{HCV}$ prevalence and hemodialysis seniority worldwide. Dussol confirms this finding in a multicentric study conducted in South-East France, where he concluded that the duration of dialysis beyond eight years is the main risk factor for HCV infection [13]. According to our study, the number of years in hemodialysis is a risk factor for $\mathrm{HCV}$ in statistical analysis $(\mathrm{p}<0.001)$. In Morocco, among hemodialysis patients at IbnSina Hospital, the average duration of dialysis in $\mathrm{HCV}+$ is 10.6 years. In our series, the median duration is 7 years, with a risk multiplied by 1.16 for each year in hemodialysis more. Seniority in hemodialysis is a major risk factor for hemodialysis patients. Older hemodialysis patients are more exposed to HCV over time. The nosocomial transmission of the virus by the dialysis machine would be a possible explanation, especially in developing countries where the introduction of universal hygiene precautions is still difficult to obtain [14]. A study conducted in Aden, Yemen in 2015 by Aman et al found that the seroprevalence of HCV infection in HDC was significantly associated with the number of attended hemodialysis centers, which is in agreement with other studies [15]. In our work, the number of centers frequented stands out as a risk factor for HCV contamination $(\mathrm{p}<0.001)$. We can put the result of our study in the context of a decrease in seroprevalence according to the year of study at the national level. This can be explained by taking the following steps: - serological screening of anti-HCV antibodies in blood donors, established since 1994 - the use of erythropoietin to treat anemia secondary to renal failure - the respect of the rules of universal hygiene: The human factor constitutes an angular piece in the transversal transmission of the virus in the centers of hemodialysis. Medical and paramedical personnel must be made aware of the respect of universal hygiene measures in order to avoid the transmission of HCV by hands, instruments soiled with blood and untimely manipulation $[16,17]$.

\section{Conclusion}

In hemodialysis, the risk of infection, and particularly by $\mathrm{HCV}$ is very high. The repeated vascular approach and the immunosuppression potentiate this risk. However, this intrinsic susceptibility of the patients can't explain alone, the high rates of seroprevalence reported in these patients.

In our study, the seroprevalence of viral hepatitis $\mathrm{C}$ in hemodialysis patients determined by chemiluminescence microparticulate immunoassay (CMIA) was 15\%. This prevalence is lower than those reported in other moroccan studies reported in developed countries, where it does not exceed $10 \%$. But these prevalence figures remain higher 
compared to the general population of Morocco, where the prevalence of $\mathrm{HCV}$ is estimated at $1.93 \%$.

This study shows that the main risk factors for $\mathrm{HCV}$ infection in chronic hemodialysis patients are seniority in hemodialysis and the number of hemodialysis centers attended. This study also shows that blood transfusion is no longer a major risk factor. This is explained by the introduction of systematic screening of anti-HCV antibodies since 1994 in blood donors in Morocco.

It is important to remember that the transmission of $\mathrm{HCV}$ in hemodialysis is not inevitable and that it can be avoided, if not at least limited, by the regular screening of HIV-positive patients and the strict and rigorous application of universal rules of hygiene.

\section{Conflicts of Interest}

All the authors do not have any possible conflicts of interest.

\section{References}

[1] Global Hepatitis Report 2017. Geneva: World Health Organization; 2017.

[2] Kamar N, Izopet J, Rostaing L. Prévalence et incidence du virus de l'hépatite $\mathrm{C}$ en hémodialyse : dépistage et prévention. Néphrologie \& Thérapeutique. 2008 ; 4: 89-91.

[3] Sekkat S, Kamal N, Benali B, Fellah H, Amazian K, Bourquia A. Prévalence des anticorps anti-VHC et incidence de séroconversion dans cinq centres d'hémodialyse au Maroc. Néphrologie \& thérapeutique. 2008 ; 4: 105-10.

[4] Rahnavardi M, HosseiniMoghaddam SM, AlavianSM. Hepatitis $\mathrm{C}$ in hemodialysis patients: Current global magnitude, natural history, diagnostic difficulties, and preventive measures. Am. J. Nephrol. 2008; 28: 628-40.

[5] Prakash S, Jain A, Sankhwar SN, Usman K, Prasad N, SahaD. Prevalence of hepatitis B \& C viruses among patients on hemodialysis in Lucknow, Uttar Pradesh. Clin. Epidemiol. Glob. Heal. 2014; 2: 19-23.

[6] Alashek W a, McIntyre CW, TaalMW. Hepatitis B and C infection in haemodialysis patients in Libya: prevalence, incidence and risk factors. BMC Infect. Dis. 2012; 12: 265.
[7] Vidales-Braz B, da Silva N, Lobato R, Germano F, da Mota L, Barros E. Detection of hepatitis $\mathrm{C}$ virus in patients with terminal renal disease undergoing dialysis in southern Brazil: prevalence, risk factors, genotypes, and viral load dynamics in hemodialysis patients. Virol J. 2015; 12: 8.

[8] Boulaajaj K, Elomari Y, Elmaliki B, Madkouri B, Zaid D, BenchemsiN. Infectionsvirales : VHC, VHB et VIH chez les hémodialyses, CHU Ibn-Rochd, Casablanca. Néphrologie\&thérapeutique. $2005 ; 1:$ 274-84.

[9] Abdelaali, B., Omar, M., Taoufik, D., Samir, A., Saad, M., \&Benyahia, M. Hepatitis C Viral Prevalence and Seroconversion in Moroccan Hemodialysis Units: Eight Year Follow Up. Journal of Medical Diagnostic Methods, 2013.91.

[10] El Harraqui R, Karimi I, Benabdellah N, Khanfri N, Bentata Y, Haddiya I. Hépatite virale $\mathrm{C}$ en hémodialyse chronique: prévalence et facteurs de risques. Néphrologie \& thérapeutique. 2012; 8: 397.

[11] Benouda A, Boujdiya Z, Ahid S, Abouqal R, Adnaoui M. Prévalence de l'infection par le virus de l'hépatite-C au Maroc et évaluation des tests sérologiques de dépistage pour la prédiction de la virémie. Pathol. Biol. 2009; 57: 368-72.

[12] Bahadi A, Maoujoud O, Zejjari Y, Alayoud A, Hassani K, Elkabbaj D. Diagnostic et évaluation de l'hépatite virale C chez l'hémodialysé/Diagnosis and evaluation of hepatitis $\mathrm{C}$ virus among haemodialysis patients. East. Mediterr. Heal. J. $2013 ; 19: 192$.

[13] Dussol B, Brunet P, Berthezen P. Infection par le virus de l'hépatite $\mathrm{C}$ chez les dialysés chroniques multicentrique de la région Sud-Est de la France. XVI e Symp. Gambro, SaintÉtienne. 1995. p. 106-11.

[14] Su Y, Yan R, Duan Z, Norris JL, Wang L, Jiang Y. Prevalence and risk factors of hepatitis $\mathrm{C}$ and $\mathrm{B}$ virus infections in hemodialysis patients and their spouses: A multicenter study in Beijing, China. J. Med. Virol. 2013; 85: 425-32.

[15] Aman K, Al-Dubai SA, Aman R, Hawash A, Alshagga M, KassimS. Prevalence and associated factors of hepatitis C virus infection among renal disease patients on maintenance hemodialysis in three health centers in Aden, Yemen: a cross sectional study. Saudi J Kidney Dis Transpl. 2015; 26: 380-5.

[16] Vallet-Pichard A, Pol S. Prise en charge de l'infection par les virus des hépatites $\mathrm{B}$ ou $\mathrm{C}$ chez l'insuffisant rénal chronique. Néphrologie \& thérapeutique. 2015 ; 11: 507-20.

[17] Dalibon P. L'infection par le virus de l'hépatite C. Actual. Pharm. 2016; 55: 18-20. 